\title{
Intra-annual and intra-seasonal flow dynamics of a High Arctic polythermal valley glacier
}

\author{
Robert G. BINGHaM, ${ }^{1}$ Peter W. NienOW, ${ }^{1}$ MartinJ. SHARP ${ }^{2}$ \\ ${ }^{1}$ Department of Geography and Topographic Science, University of Glasgow, Glasgow G12 8QQ, Scotland \\ E-mail:rbingham@geog.gla.ac.uk \\ ${ }^{2}$ Department of Earth and Atmospheric Sciences, University of Alberta, Edmonton, Alberta T6G 2E3, Canada
}

\begin{abstract}
Measurements of surface dynamics on polythermal John Evans Glacier, Nunavut, Canada, over two winter periods and every 7-10 days throughout two melt seasons (June-July 2000, 2001) provide new insight into spatio-temporal patterns of High Arctic glacier dynamics. In the lower ablation zone, mean annual surface velocities are $10-21 \mathrm{~m} \mathrm{a}^{-1}$, but peak velocities up to $50 \%$ higher are attained during late June/early July. In the upper ablation zone and lower accumulation zone, mean annual surface velocities are typically $10-18 \mathrm{~m} \mathrm{a}^{-1}$, and peak velocities up to $40 \%$ higher occur during late July. In the upper accumulation zone, mean annual surface velocities are $2-9 \mathrm{~m} \mathrm{a}^{-1}$, and motion in mid- to late July exceeds this by up to $10 \%$. Rapid drainage of ponded supraglacial water in the upper ablation zone to an initially distributed subglacial drainage system in mid-June may force excess surface motion in the warm-based lower glacier. The data indicate that the duration of the velocity response may be related to the rate of channelization of the basal drainage, and the velocity response may be transmitted up-glacier by longitudinal coupling. An increase in surface velocities in the middle glacier in late July occurs in conjunction with the opening of two further moulins in the accumulation zone.
\end{abstract}

\section{INTRODUGTION}

Recent models of climate change have identified the High Arctic (the global area north of $75^{\circ} \mathrm{N}$ ) as highly sensitive to predicted global warming (Hardy and Bradley, 1996; Houghton and others, 2001). The resultant melting of High Arctic ice cover (comprising an area of $\sim 275000 \mathrm{~km}^{2}$, excluding Greenland) may contribute to eustatic sea-level rise of 0.5-1.5 m (Prowse, 1990; Munro, 2000). However, it is unclear how rapidly glaciers and ice caps in the High Arctic will respond to climatic warming, due in part to limited knowledge of the dynamics of High Arctic glaciers. Largely due to a dearth of field data with which to parameterize model inputs, temporal variations in High Arctic ice flow, and coupling between dynamics and hydrology in High Arctic glaciers, have been little considered in recent models of cryospheric response to climate change (Houghton and others, 2001). By influencing mass transfer to lower altitudes, these factors may provide a critical mechanism for rapid, largescale responses of glaciers and ice sheets to climatic warming (Zwally and others, 2002). This paper goes some way towards addressing these issues by investigating intra-annual and intra-seasonal variations in glacier motion and hydrology over two melt seasons at a High Arctic glacier.

In this paper, we define a "High Arctic glacier" as a polythermal glacier comprised almost entirely of cold ice, but containing a basal layer of warm ice underneath the ablation zone. Such a thermal regime is characteristic of many glaciers in the Canadian High Arctic, northern Alaska, Greenland and Svalbard (Blatter and Hutter, 1991, fig. 1), and is exemplified by White Glacier, Axel Heiberg Island (Blatter, 1987); McCall Glacier, northern Alaska (Rabus and Echelmeyer,
1997); Finsterwalderbreen, Svalbard (Wadham and others, 2001); and John Evans Glacier, Ellesmere Island (Copland and Sharp, 2001).

Intra-annual and intra-seasonal variations in the surface dynamics of temperate glaciers have been attributed to the spatially extensive penetration of supraglacial meltwaters to the glacier bed during each melt season (Willis, 1995; Fountain and Walder, 1998). Peak surface velocities are typically observed shortly after the onset of melt, as large surface meltwater inputs encounter a predominantly distributed subglacial drainage network, inducing high subglacial water pressures and enhanced basal motion (Kamb, 1987). Continued surface meltwater supplies over the melt season may induce channelization of subglacial drainage (Nienow and others, 1998), leading to a fall in water pressures and a slowdown in surface velocities (Willis, 1995). As channels are formed further up-glacier, in association with the retreat of the transient snowline, a wave of high basal water pressures/ high surface velocities may move up-glacier as the melt season progresses. Velocities remain low outside the melt season as channels close due to the influence of overburden pressures (Fountain and Walder, 1998). Whether similar processes occur at High Arctic glaciers is unclear, because surface inputs (moulins/crevasses) tend to be few and widely spaced (due to lower rates of glacier activity), and basal motion may be precluded in many areas by cold-based ice.

Previous observations of High Arctic glacier flow dynamics have demonstrated that surface motion varies intraannually, at least in the ablation zone, where ice is warmbased (Müller and Iken, 1973; Rabus and Echelmeyer, 1997; Copland, 2001; Zwally and others, 2002). Peak glacier surface velocities during summer melt seasons have variously been 

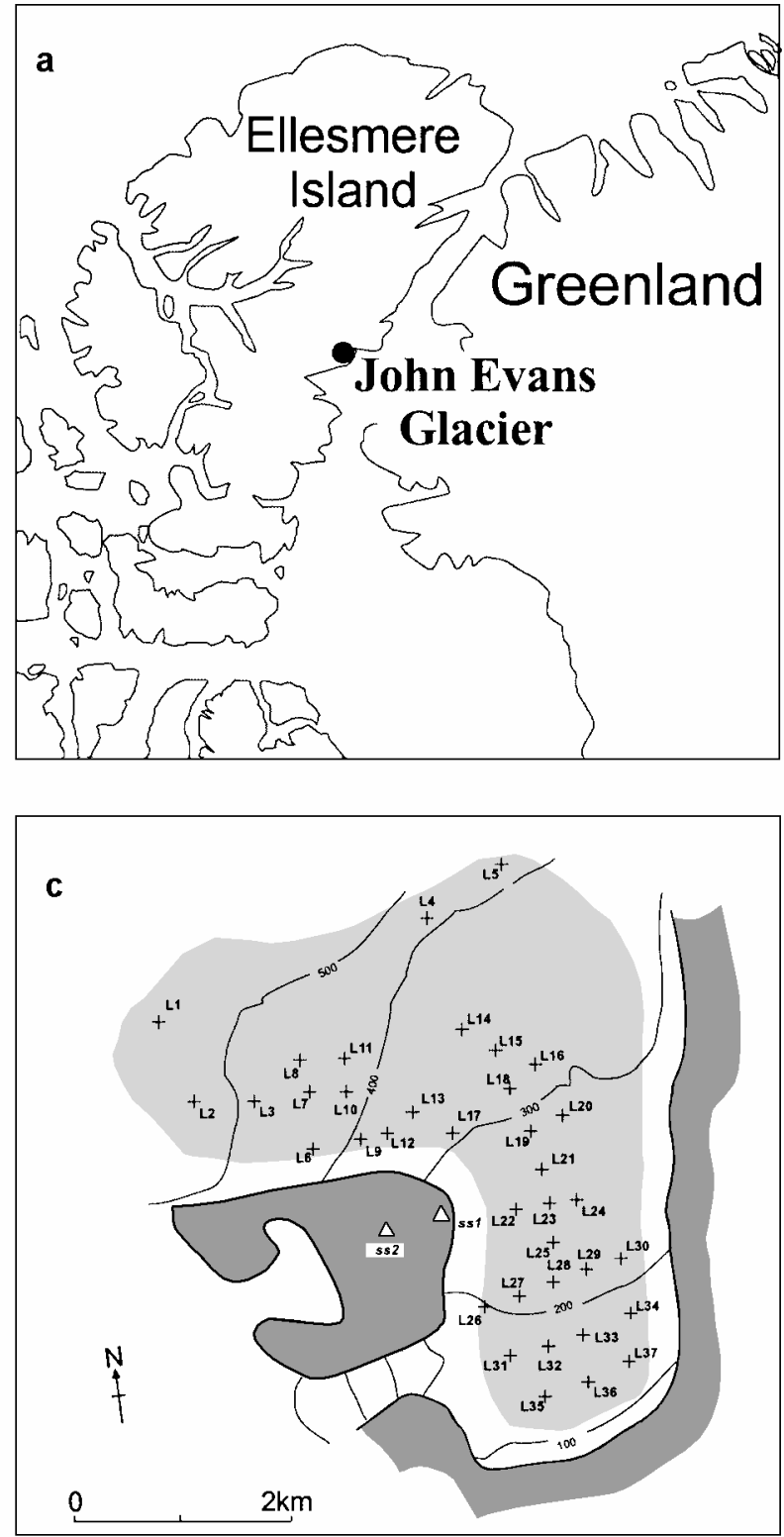

observed to coincide with: (i) peaks in water levels measured in moulins (Iken, 1972); (ii) peaks in supraglacial discharges entering moulins and crevasses (Copland, 2001); and (iii) peaks in rates of surface melting (Zwally and others, 2002). These observations suggest that, as at temperate glaciers, hydrologically induced variations in basal motion are predominantly responsible for variations in surface dynamics.

This paper reports on glacier-wide variations in intraannual and intra-seasonal surface dynamics measured at John Evans Glacier, Nunavut, Canada, from late July 1999 to late July 2001. The measurements formed one component of an integrated study of the hydrology and dynamics of this High Arctic glacier, the main hydrological results of which will be presented elsewhere. The specific purposes of this study were to elucidate: (i) whether surface motion varies spatially and/or temporally over a melt season, (ii) whether motion anomalies propagate spatially, and (iii) what mechanisms are responsible for the observed surface dynamics.

\section{FIELD SITE}

John Evans Glacier is a large valley glacier situated at $79^{\circ} 40^{\prime} \mathrm{N}$, $74^{\circ} 00^{\prime} \mathrm{W}$ on eastern Ellesmere Island, Nunavut, Canada. The glacier covers $\sim 75 \%$ of a $220 \mathrm{~km}^{2}$ catchment, has a length of

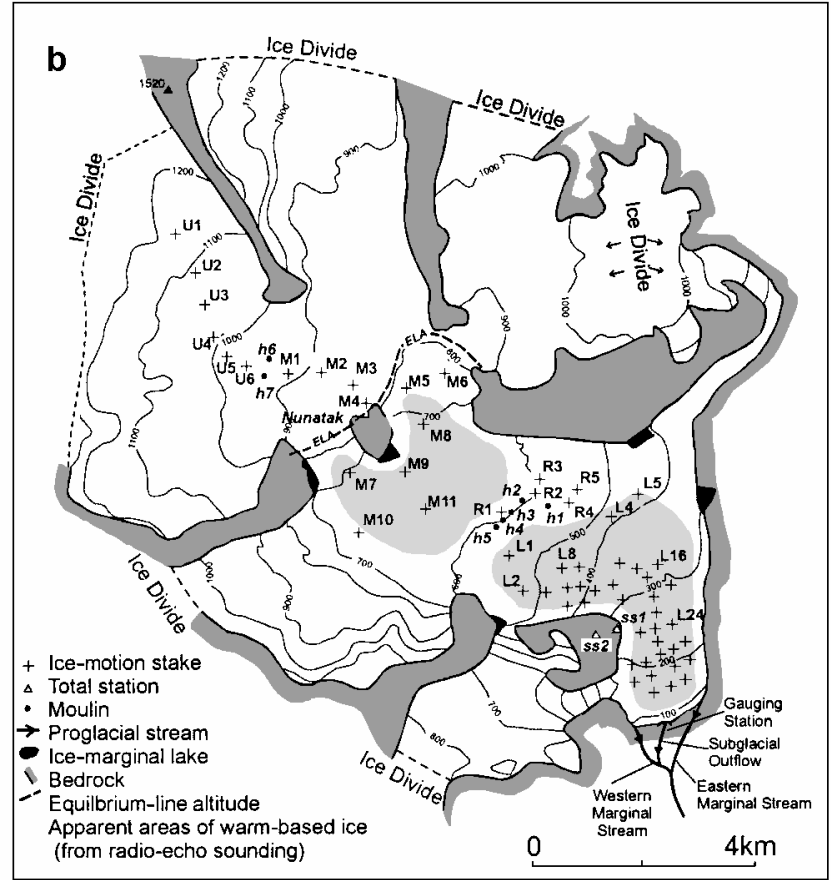

Fig. 1. (a) Location of John Evans Glacier. (b) Distribution of velocity stakes measured from 1999 to 2001. The distribution of warm-based ice is derived from radio-echo sounding undertaken by Copland and Sharp (2001). Note the locations of two moulin fields: $h 1-h 5$ are situated over a large riegel; and $h 6$ and $h 7$ are situated in the accumulation zone above a large nunatak. These moulin fields bound three sectors of the glacier: the upper glacier ( $U$ stakes; upstream of $h 6-h 7$ ), the middle glacier (M stakes; between the moulin fields) and the lower glacier ( $L$ stakes; downstream of $h 1-h 5$ ). $R$ stakes overlie a bedrock riegel, over which ice thins to $\sim 40 \mathrm{~m}$ and ice is apparently cold-based. (c) Close-up of lower-ablation-zone stake network. Legend as in ( $b$ ).

$15 \mathrm{~km}$ along its main flowline and spans an elevation range of 100- $1500 \mathrm{~m}$ (Fig. 1). The equilibrium line is located at $\sim 750$ $850 \mathrm{~m}$, next to a small nunatak (Fig. 1); the 1997-99 mean annual air temperature measured at a meteorological station located near to the equilibrium-line altitude (ELA) was $-15.2^{\circ} \mathrm{C}$. Ice thicknesses have been determined from groundbased radio-echo sounding at 3200 locations across the glacier: near to the ELA, ice is almost $400 \mathrm{~m}$ thick, but under the accumulation zone and the lower $4 \mathrm{~km}$ of the glacier, ice is typically 100-200m in depth (Copland and Sharp, 2001). However, ice thins to $\sim 40 \mathrm{~m}$ above a large bedrock riegel $\sim 4 \mathrm{~km}$ above the glacier snout.

Radio-echo sounding and $15 \mathrm{~m}$ ice temperatures suggest that the glacier is polythermal (Fig. 1). Throughout the glacier, $15 \mathrm{~m}$ ice temperatures range from $-7^{\circ}$ to $-15^{\circ} \mathrm{C}$, demonstrating that near-surface ice remains cold. In the lower ablation zone, high bed reflection powers $\left(\mathrm{BRP}_{\mathrm{r}}\right)$ (corrected for ice thickness) and an internal reflector indicate the presence of a basal layer of warm ice up to $40 \mathrm{~m}$ thick (Copland and Sharp, 2001). This warm basal layer results from pressure melting under $\sim 200 \mathrm{~m}$ of ice. Further up-glacier, high $\mathrm{BRP}_{\mathrm{r}}$ occurs in the absence of an internal reflector, suggesting that only the basal interface is warm (Copland and Sharp, 2001). Near to the margins and terminus, and over the riegel, 
ice remains entirely frozen due to a steep englacial temperature gradient conducting away geothermal heat (Copland and Sharp, 2001). In the accumulation area, low $\mathrm{BRP}_{\mathrm{r}}$ has been interpreted by Copland and Sharp (2001) to suggest that ice is entirely cold. This interpretation of the thermal regime is consistent with direct borehole measurements of the thermal regime of nearby White Glacier (Blatter, 1987) and Laika Ice Cap (Blatter and Kappenberger, 1988).

At the beginning of each melt season, cold ice at the terminus may act as a thermal dam to subglacial outflow, leading to the development of a temporary subglacial reservoir beneath the lower ablation zone (Skidmore and Sharp, 1999). Subglacial outflow initiates several weeks into each melt season (typically late June-early July), by forcing a path beneath, or through fractures in, the ice (Skidmore and Sharp, 1999). The source and routing of the subglacial outflow are not well understood. In 1994, 1996 and 2001, subglacial outflow throughout the melt season was intermittent and pulsed, with channel shifts between outflow events. In 1998, 1999 and 2000, subglacial outflow rapidly settled into a diurnal rhythm $(\sim 2-3$ days after initiation) which persisted throughout the melt season, and its magnitude varied in close relation with air temperatures and surface melting, strongly suggesting a supraglacial origin. Skidmore and Sharp (1999) suggested that surface runoff draining into moulins located in a crevasse field overlying the bedrock riegel (moulins h1-h5; Fig. l) might constitute the origin of much, if not all, of the subglacial outflow, which may temporarily shut down in cooler summers due to low rates of surface runoff. Copland (2001) demonstrated that intra-annual contrasts between summer (July) and winter (August-May) surface velocities along the main flowline were greatest down-glacier of these moulins. Above the riegel, it was concluded that internal deformation could account for all surface motion, although longitudinal stress-gradient coupling ensured that summer velocities exceeded winter velocities up to the upper accumulation zone.

At the onset of the 2000 and 2001 melt seasons, all moulins were inactive, having been sealed by snow and ice during the preceding winter. Runoff generated in the lower ablation zone drained supraglacially throughout each melt season. (Throughout this paper, "lower ablation zone" refers to the area between the terminus and the riegel moulins hlh5 (Fig. 1). Additionally we refer to the "upper ablation area", between $\mathrm{hl}-\mathrm{h} 5$ and the ELA; the "lower accumulation area" from the ELA to the upper moulins, h6 and h7; and the "upper accumulation area" from h6 and h7 to the glacier head (Fig. 1b).) Surface melt generated in the upper ablation area and throughout the accumulation zone initially refroze in the cold snowpack and subsequently collected in large supraglacial ponds which built up along relict stream networks between the nunatak and the riegel. Over $2-3$ weeks, these ponds became connected along a series of initially snow-plugged englacial channels. Each year, on 21 June 2000 and 28 June 2001 respectively, five large moulins (hl-h5; Fig. 1b) opened suddenly in a crevasse field over the riegel, and the network of supraglacial ponds (combined capacity $\sim 200000 \mathrm{~m}^{3}$ ) drained rapidly (over 24 hours) into the englacial system. Following these large drainage events, supraglacial streams developed along the network of supraglacial pond basins and continued to drain into hl-h5 for the remainder of the melt season. Further up-glacier, two additional moulins (h6, h7: Fig. lb) opened between 5-19 July and 13-21 July in 2000 and 2001 respectively (the exact
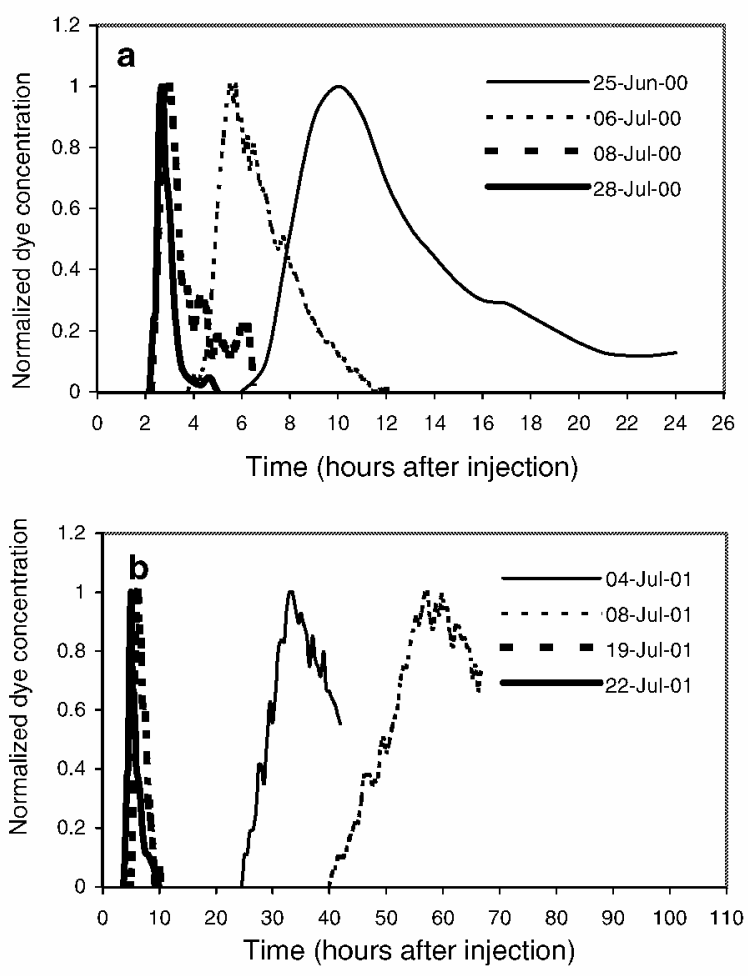

Fig. 2. Breakthrough curves derived from dye injected into moulin h1 and detected in the subglacial outflow during (a) 2000 and (b) 2001. Note the difference in $x$-scales. Dye curves from 2000 demonstrate clear evolution of the basal drainage system. In 2001, basal drainage remained distributed through early fuly, and rationalized in mid-fuly after the resumption of high meltwater inputs.

dates on which each opened are unknown), capturing large supraglacial streams (combined discharge $\sim 5 \mathrm{~m}^{3} \mathrm{~s}^{-1}$ ) draining the accumulation zone.

In 2000 and 2001, subglacial outflow at the terminus initiated on 22 June and 29 June respectively (subglacial outflow having been completely inactive during winter). In both cases, subglacial outflow initiated $<24$ hours after the sudden drainage of the large supraglacial ponds into the riegel moulins (hl-h5) 5 km up-glacier. Rhodamine-WT dye, subsequently injected into moulins $\mathrm{hl}-\mathrm{h} 4$ during June-July 2000 and into hl during July 2001, was later detected in the subglacial outflow using a St Johns Fluoro-Tec field fluorometer, confirming that supraglacial meltwaters entering these moulins accessed the subglacial drainage system between the riegel and the terminus. Dye injected into h6 in late July 2000 was also subsequently detected in the subglacial outflow, demonstrating that surface runoff entering a moulin in the accumulation zone also accessed the subglacial drainage system. Periodic dye injections into hl throughout the 2000 melt season indicated that the subglacial drainage system beneath the lower ablation zone rapidly became channelized following the initiation of subglacial outflow (Fig. 2a). However, similar experiments in 2001 demonstrated that the subglacial drainage system remained largely distributed, as a result of cool weather significantly reducing surface runoff during much of early July (Fig. 2b).

The hydrological observations from 2000 and 2001 raise several important questions. Firstly, surface meltwaters clearly access the subglacial drainage system following two large drainage events each year, via $\mathrm{hl}-\mathrm{h} 5$ in mid- to late June and via h6 and h7 in mid- to late July. Do these 
drainage events produce varying dynamic responses in different parts of the glacier, according to location upstream or downstream of the lower and/or upper moulin fields? Secondly, surface runoff may access the subglacial drainage system via h6 and h7 where radio-echo sounding suggests that ice is cold-based. Could this account for surface motion variations upstream of the bedrock riegel? Thirdly, what is the effect of subglacial drainage-system evolution on surface dynamics in the lower ablation zone? This paper addresses these questions by analyzing glacier-wide surface dynamics measured at John Evans Glacier from the end of the 1999 melt season through to the end of the 2001 melt season.

\section{METHODS}

Sixty velocity stakes were drilled and frozen into the ice surface throughout the glacier towards the end of 1999 (Fig. 1). The stakes were labelled as follows:

(i) U stakes - situated in the upper accumulation zone;

(ii) $\mathrm{M}$ stakes - situated between the bedrock riegel and moulins h1-h5, but down-glacier of h6-h7;

(iii) $\mathrm{R}$ stakes - overlying the bedrock riegel, and surrounding moulins hl-h5;

(iv) L stakes - situated in the warm-based lower ablation zone, downstream of all known supraglacial meltwater inputs.

Stake positions were measured once towards the end of the 1999 melt season, and every 7-10 days during the 2000 and 2001 melt seasons.

A Leica System 500 differential global positioning system (GPS) was used to monitor the positions of all stakes, with the exceptions of L3 and L6-L37 (discussed below). The procedure involved leaving a "reference" GPS receiver to fix a known position on bedrock throughout each survey, whilst placing the "roving" GPS receiver adjacent to each survey stake for up to $40 \mathrm{~min}$ to obtain each individual stake position. To ensure consistency between surveys, the GPS receiver was placed vertically just above the ice or snow surface adjacent to the north side of each stake, and the distance to the top of the stake from the receiver was measured manually. This gave the $x y z$ position of the top of the stake for each survey, reducing errors associated with tilting of the stakes due to wind or melt-out, which would be accentuated if the receiver were placed at the top of the stake. Systematic errors for individual surveys were reduced by surveying three fixed survey points on bedrock with the roving GPS receiver during each GPS survey. Estimates of errors associated with the GPS system itself were directly calculated by the unit itself. Where positional errors exceeded $5 \mathrm{~mm}$, the result was classed as "ambiguous" and was not considered further in the analysis. The average error for the positioning of a stake was $\pm 2.04 \mathrm{~mm}$, equating to a maximum between-survey displacement error of $4.08 \mathrm{~mm}$, assuming successive position errors are of opposite sign. Over a 7 day summer measurement period (the smallest measurement interval in this analysis), this produced a maximum mean velocity error of $0.21 \mathrm{~m} \mathrm{a}^{-1}$; over longer measurement intervals this error was reduced further. To be considered "real", variations in velocities between periods of observation must exceed these errors. (It should be noted, however, that poor satellite configurations may occasionally lead to apparently unambiguous, i.e. not detected by the GPS system, systematic errors during parts of a day. This means that care must be taken not to rely on individual survey stakes to define motion trends.)

Stakes L3 and L6-L37 each had a reflecting prism attached, and prism positions were periodically surveyed using a total station instrument (Geodimeter System 500). The total station was mounted on tripods on bedrock at ss1 to survey L12-L37, and at ss2 to survey L3 and L6-L11 (Fig. 1c) (line-of-sight problems necessitated the use of two survey stations). Repeat surveys to three separate reference targets, located on the surrounding bedrock, allowed for determination of, and compensation for, errors associated with setting up the total station on each survey tripod, and with changes in temperature and pressure during a survey. Each velocity stake was surveyed at least twice during a survey; the $x, y$ and $z$ coordinates were taken as the mean, and the error associated with each coordinate value was calculated as the standard deviation of this mean value. The average error for the position of each survey stake from all surveys was $\pm 8.61 \mathrm{~mm}$. Again assuming that successive errors are of opposite sign, this yielded a maximum between-survey displacement error of $17.22 \mathrm{~mm}$, producing a maximum mean velocity error of $0.90 \mathrm{~m} \mathrm{a}^{-1}$ over a 7 day measurement period. These errors are insignificant in comparison with observed velocities. Errors derived from the total station itself were neglected as they were significantly smaller than measurement errors.

\section{RESULTS}

To test whether surface flow in different parts of John Evans Glacier responded to temporal variations in supraglacially derived basal hydrological forcing, each year was split into the following time periods:

(i) "Winter" - the period between the final survey of one melt season and the initial survey of the following melt season (i.e. end July/start August to early June);

(ii) "Early spring" - early June, from the onset of surface melting to the onset of meltwater drainage into moulins hl-h5;

(iii) "Spring event" - time period surrounding initial drainage of supraglacial meltwaters into moulins hl-h5;

(iv) "Mid-summer" - early to mid-July, when meltwaters continue to drain into $\mathrm{h} 1-\mathrm{h} 5$ and the snowline retreats up-glacier;

(v) "Late summer" - time period following drainage of supraglacial meltwaters into up-glacier moulins h6 and $\mathrm{h} 7$.

Time constraints precluded the possibility of surveying all 60 stakes on a single day, so, for example, the period "early spring 2000" at stake U3 is slightly offset from "early spring 2000" at stake M8. The exact time periods covered by winter, early spring, etc., for each stake are detailed in Table 1. As the temporal offsets are small (typically 1-2 days between different stakes) in comparison to the duration of each time period, we assume they are negligible and that winter, early-spring, etc., velocities are directly comparable between all survey stakes.

Mean annual surface velocities for all stakes on John Evans Glacier from 1999 to 2001 are plotted in Figure 3a. Also provided are surface velocities during different periods 
Table 1. Division of specific periods over which velocities were measured at each survey stake

\begin{tabular}{|c|c|c|c|c|c|}
\hline Stakessurveyed & Winter 1999/2000 & Early spring 2000 & Spring event 2000 & Mid-summer 2000 & Late summer 2000 \\
\hline All U stakes, M1-M4 & 3 Aug. 1999-4 Jun. 2000 & 4 Jun. 2000-14 Jun. 2000 & 14 Jun. 2000-5 Jul. 2000 & 5 Jul. 2000-19 Jul. 2000 & 19 Jul. 2000-30 Jul. 2000 \\
\hline $\begin{array}{l}\text { M5-M11, R1-R5, } \\
\text { L1, L2, L4, L5 }\end{array}$ & 31 Jul. 1999-6 Jun. 2000 & 6 Jun. 2000-14 Jun. 2000 & 14 Jun. 2000-8 Jul. 2000 & 8 Jul. 2000-23 Jul. 2000 & 23 Jul. 2000-1 Aug. 2000 \\
\hline L3, L6-L37 & 30 Jul. 1999-10 Jun. 2000 & 10 Jun. 2000-16 Jun. 2000 & 16 Jun. 2000-5 Jul. 2000 & 5 Jul. 2000-20 Jul. 2000 & 20 Jul. 2000-31 Jul. 2000 \\
\hline Stakes surveyed & Winter 2000/2001 & Early spring 2001 & Spring event 2001 & Mid-summer 2001 & Late summer 2001 \\
\hline All U stakes, M1-M4 & 30 Jul. 2000-1 Jun. 2001 & 1 Jun. 2001-19 Jul. 2001 & 19 Jul. 2001-6 Jul. 2001 & 6 Jul. 2001-21 Jul. 2001 & 21 Jul. 2001-28 Jul. 2001 \\
\hline $\begin{array}{l}\text { M5-M11, R1-R5 } \\
\text { L1, L2, L4, L5 }\end{array}$ & 1 Aug. 2000-2 Jun. 2001 & 2 Jun. 2001-24 Jun. 2001 & 24 Jun. 2001-9 Jul. 2001 & 9 Jul. 2001-18 Jul. 2001 & 18 Jul. 2001-29 Jul. 2001 \\
\hline L3, L6-L37 & 31 Jul. 2000-8 Jun. 2001 & 8 Jun. 2001-23 Jun. 2001 & 23 Jun. 2001-8 Jul. 2001 & 8 Jul. 2001-19 Jul. 2001 & 19 Jul. 2001-26 Jul. 2001 \\
\hline
\end{tabular}

of each year, shown as percentages of mean annual motion (Fig. 3b-k). (Note that these diagrams rely on interpolation between individual data points (velocity stakes) and boundaries (glacier margin), so velocity estimates away from the stake locations may be erroneous and are not considered in the analysis.) Maximum average surface velocities of 15$20 \mathrm{~m} \mathrm{a}^{-1}$ are mostly attained throughout the lower ablation zone, below the bedrock riegel and all moulins, where ice is probably warm-based (Fig. 3a). However, relatively fastmoving surface ice $\left(\sim 17 \mathrm{~m} \mathrm{a}^{-1}\right)$ is also located just downglacier of the upper moulins at stakes M2 and M3. The slowest-moving stakes are situated (i) in the upper accumulation zone upstream of all known moulins (U stakes); (ii) in locations peripheral to the main flowline (M10, L5); and (iii) immediately up-glacier and down-glacier of the nunatak, which retards flow in these locations (M4, M9). (In fact, stakes M4 and M9 are virtually stationary and are therefore excluded from further analysis.)

Almost all stakes, regardless of location, flowed considerably faster during the melt season compared with over winter (Fig. 3). Stakes in the lower ablation zone (L stakes) experienced peak velocities during the spring event in 2000 (Fig. 3d) and during mid-summer in 2001 (Fig. 3j). In 2000, this was followed by a slow-down during mid-summer (Fig. 3e) and a speed-up in late summer (Fig. 3f). In 2001, high surface velocities were maintained in the lower ablation zone throughout mid- to late summer (Fig. $3 \mathrm{j}$ and k). Velocity variations over the middle glacier ( $\mathrm{R}$ and $\mathrm{M}$ stakes) mostly experienced the same annual cycle as stakes in the lower glacier, but the variations were strongly damped. However, a period of high velocities during late summer was superimposed on this signal (Fig. 3f and k). Stake motion in the upper glacier (U stakes) experienced only slight fluctuations, although motion in summer exceeded that in winter (Fig. 3).

\section{DISGUSSION}

The observed intra-annual and intra-seasonal surface dynamics at John Evans Glacier relate closely to the spatial distribution and timing of supraglacial meltwater inputs to the subglacial drainage system. During winter 1999/2000 (Fig. 3b), and early spring 2000 (Fig. 3c), prior to supraglacial drainage into $\mathrm{hl}-\mathrm{h} 5$, surface velocities throughout the glacier differed little from mean annual velocities. However, from late June to early July 2000 (i.e. spring event
2000), surface velocities in the lower ablation zone increased by up to $60 \%$, whilst surface velocities in the upper ablation zone and lower accumulation zone increased by up to $25 \%$ (Fig. 3d). The distinct increase in surface velocities in the lower ablation zone during the spring event likely resulted from enhanced basal motion induced by rising subglacial water pressures in a hydraulically inefficient basal drainage system (cf. Kamb, 1987). These high pressures were induced by the rapid ( $\sim 24$ hours) drainage of up to $200000 \mathrm{~m}^{3}$ of ponded supraglacial meltwaters, via $\mathrm{hl}-\mathrm{h} 5$, to the glacier bed on 21 June 2000. That these meltwaters initially encountered a distributed drainage system underneath the lower ablation zone was confirmed by a dye-tracer test on 25 June 2000, which showed that the subglacial drainage system between $\mathrm{hl}$ and the terminus was relatively inefficient shortly after the onset of drainage into hl (Fig. 2a). The damped increase in surface velocities up-glacier of the riegel (Fig. 3d) may have resulted from longitudinal stress-gradient coupling with the hydrologically forced velocity anomalies occurring down-glacier.

In mid-summer 2000, surface velocities throughout the glacier exceeded mean annual velocities, but motion in the lower ablation zone slowed down relative to the spring event (Fig. 3e). This may be explained by considering the changing form of the subglacial drainage system during summer 2000. Dye-tracing experiments from moulin hl confirmed that persistently high surface runoff throughout summer 2000 led to rapid channelization of the subglacial drainage system beneath the lower ablation zone during late June and throughout July (Fig. 2a). This rationalization of the subglacial drainage system in the lower ablation zone reduced subglacial water pressures in mid-summer, thereby reducing basal motion and leading to the observed reduction in surface velocities.

In late summer 2000, surface velocities in the lower ablation zone once again increased, but this time in conjunction with peak surface velocities recorded in the upper ablation zone and lower accumulation zone (Fig. 3f). This late-summer velocity increase throughout much of the glacier may be attributed to the opening of $h 6$ and $h 7$, in the accumulation zone, in mid-July. Combined discharges into these moulins through late July typically attained values of $\sim 5 \mathrm{~m}^{3} \mathrm{~s}^{-1}$. As stated earlier, high $\mathrm{BRP}_{\mathrm{r}}$ suggest warm-based ice underlies much of the ablation zone up to and around the sides of the nunatak (Copland and Sharp, 2001), allowing for the possibility of subglacial drainage 


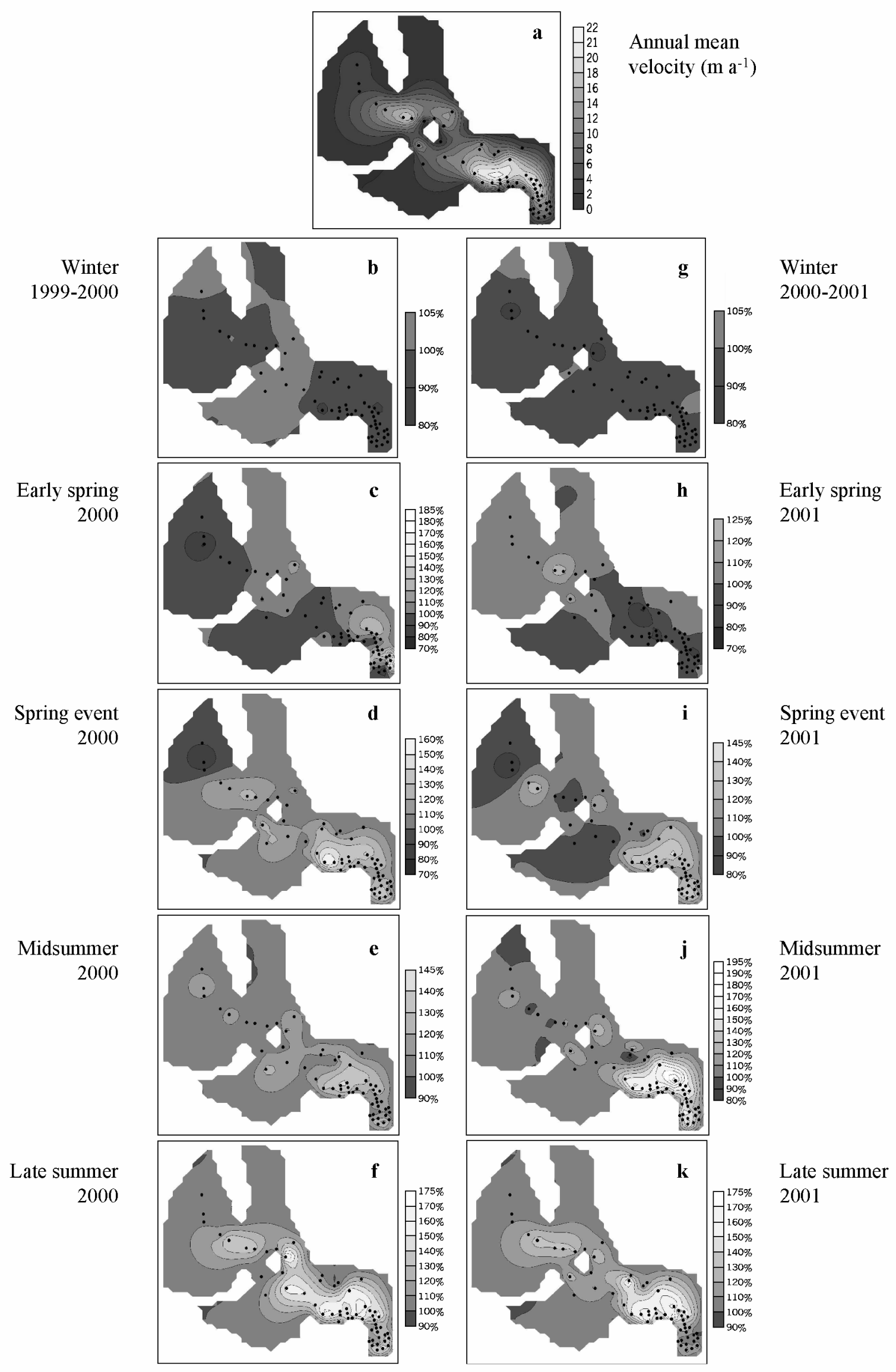

Fig. 3. (a) Distribution of mean annual velocities (in m a $a^{-1}$ ) at John Evans Glacier measured from 1999 to 2001. The black dots represent velocity stakes. Due to the method of interpolation, velocities away from the concentration of data points (velocity stakes; margins) may be inappropriate and are not considered in the analysis. $(b-k)$ Surface velocity distributions at different stages of 2000 and 2001, as percentages of mean annual velocity (100\% = mean annual velocity). Specific periods over which velocities were measured at each stake are given in Table 1. 
beneath much of the upper ablation zone (Fig. 1). Moreover, a late-July dye injection into h6 demonstrated that meltwaters draining into h6 travelled to the subglacial outflow via a partially distributed drainage system. Therefore, the opening of h6 and h 7 in mid-July likely led to increased subglacial water pressures in a distributed basal drainage system under much of the upper ablation zone, inducing high surface velocities down to the riegel. Below the riegel, an efficient, channelized drainage system underlay the lower ablation zone by late summer 2000 (Fig. 2a). However, a sudden increase in subglacial discharge of $\sim 5 \mathrm{~m}^{3} \mathrm{~s}^{-1}$, derived from supraglacial drainage into $\mathrm{h} 6$ and $\mathrm{h} 7$, may have led to a significant rise in subglacial water pressures due to the inability of the channelized system to transmit all of the enhanced discharge efficiently, resulting in a resumption of high surface velocities (Fig. 3f).

The late-summer velocity peaks in the lower accumulation zone (stakes M1-M3; Fig. 3f) are noteworthy, since they overlie ice which has been interpreted, from low $\mathrm{BRP}_{\mathrm{r}}$, to be cold-based (Copland and Sharp, 2001). The late-summer velocity peaks at these stakes are $30-40 \%$ greater than mean annual flow rates (Fig. 3f), strongly suggesting that basal motion forms a significant component of late-summer motion. Three possibilities exist to explain these phenomena. Firstly, if the radar data have been misinterpreted, the glacier may in fact be warm-based under the lower accumulation zone. In this case, surface melt penetrating to the base via $\mathrm{h} 6$ and $\mathrm{h} 7$ could perturb the basal drainage system underlying the lower accumulation zone. This would imply either that low $\mathrm{BRP}_{\mathrm{r}}$ measured in this area (Copland and Sharp, 2001) resulted from englacial attenuation of the radar signal rather than cold-based conditions, or that the warm basal interface was too thin or patchy to cause strong bed reflection powers. The possibility of warm-based ice under the accumulation zone was previously discounted, as it is inconsistent with the directly measured thermal regime of nearby White Glacier and Laika Ice Cap (Copland and Sharp, 2001). However, direct measurements or thermomechanical modelling of the thermal regime of John Evans Glacier are required to resolve this issue. A second possibility is that the glacier is indeed cold-based in the lower accumulation area and that the surface motion peaks result from longitudinal stress-gradient coupling with down-glacier motion anomalies. However, a comparison of winter (August-May) and summer (July) motion by Copland (2001) has demonstrated that the glacier has a coupling length scale of only $\sim 2 \mathrm{~km}$, making this option unlikely. A third possibility is that surface runoff (combined discharge $\sim 5 \mathrm{~m}^{3} \mathrm{~s}^{-1}$ ) captured suddenly by h6 and h7 in mid- to late July propagates rapidly via hydrofracture along a relict crevasse to the base, where it melts a conduit rapidly down-glacier to connect with warm-based ice downstream. Weertman (1973) and Scambos and others (2000) have shown that water-filled crevasses may propagate by hydrofracture to the base of a glacier, while Skidmore and Sharp (1999) invoked hydrofracture as a means by which subglacial meltwaters initially breach cold ice at the terminus of John Evans Glacier. As long as propagation is rapid, and high water supply is maintained, advection of surface heat, viscous dissipation of heat and latent heat generated by refreezing may be sufficient to counteract wholesale freezing of subglacial water flow in localized areas. During the initial stages of conduit growth, high subglacial water pressures may induce localized high motion in the lower accumulation zone. To determine which of the above hypotheses best explains the late-summer motion peaks is beyond the scope of this paper, although the correlation of the motion peaks with the onset of drainage into the upper moulins in both years suggests that the onset of drainage into h6 and h7 is significant.

Throughout summer 2000, the glacier surface in the upper accumulation zone (above moulins h6 and h7) moved only slightly faster than in winter $(<10 \%$ faster than mean annual velocity) (Fig. $3 \mathrm{e}$ and $\mathrm{f}$ ). This is consistent with the hypothesis that upstream of all known moulins small surface flow variations might be explicable entirely by longitudinal coupling with hydrologically forced events downstream.

The spatio-temporal pattern of surface velocity variations throughout summer 2001 differed slightly from that exhibited in 2000, but many of the broad-scale conclusions relating to supraglacial hydrological forcing are similar. As in 2000, surface velocities prior to the spring event differed little from mean annual velocities (Fig. $3 \mathrm{~g}$ and $\mathrm{h}$ ). Also as in the previous year, a velocity increase of up to $40 \%$ occurred in the lower ablation zone during the spring event, with small increases in velocity (up to $20 \%$ ) occurring in the upper ablation zone and lower accumulation zone (Fig. 3i). This may once again be attributed to the rapid drainage of $\sim 200000 \mathrm{~m}^{3}$ of ponded supraglacial meltwaters into h1-h5 (this time on 28 June) inducing high subglacial water pressures under the lower ablation zone; the resultant velocity response being transmitted up-glacier by longitudinal coupling.

In 2001, in contrast to 2000, surface velocities in the lower ablation zone continued to rise in mid-summer, in some locations reaching almost double the mean annual surface velocity (Fig. 3j). This contrast with the slow-down observed in mid-summer 2000 (Fig. 3e) resulted from a contrasting subglacial drainage configuration underneath the lower ablation zone. In 2001, cold weather from late June to mid-July, almost immediately following the drainage event into $\mathrm{hl}-\mathrm{h} 5$, precluded the development of a hydraulically efficient channelized subglacial drainage system to the subglacial outflow until late summer. Instead, dye-tracing experiments from hl confirm that subglacial drainage remained distributed until late July (Fig. 2b), allowing high subglacial water pressures to maintain high basal motion throughout mid-summer (Fig. 3j). Channelization of the basal drainage system only took place after mid-July, when warm weather resumed and high meltwater volumes entered hl-h5 (Fig. 2b).

In late summer 2001, the surface velocity distribution (Fig. 3k) once again mirrored that of the previous year (Fig. 3f). As in 2000, peak velocities up to $30 \%$ greater than mean velocities (Fig. $3 \mathrm{k}$ ) in the lower accumulation zone may be linked with the onset of drainage into moulins $\mathrm{h} 6$ and h7 in mid-July. Again, this induced a velocity response throughout the ablation zone (Fig. 3k) as the basal drainage system attempted to adjust to a rapid increase in up-glacierderived discharges.

\section{GONGLUSIONS}

Observed intra-annual and intra-seasonal variations in surface flow dynamics at John Evans Glacier are related primarily to the spatio-temporal pattern of supraglacial meltwater inputs to the glacier base. Specific patterns of supraglacial hydrological forcing may vary between years, leading to contrasting patterns of surface dynamics. Each spring (typi- 
cally mid- to late June), large volumes of supraglacially ponded meltwaters in the upper ablation zone drain into a distributed subglacial drainage system, inducing high subglacial water pressures and enhanced basal motion in the warm-based lower ablation zone. This causes surface velocities throughout the lower ablation zone to increase by up to $50 \%$ in spring (Fig. $3 \mathrm{~d}$ and i). Throughout late June and early July, surface velocities in the lower ablation zone exceed mean annual velocities, but the specific velocity distribution is a function of the degree of channelization (and thus hydraulic efficiency) of the basal drainage system, which influences the magnitude of subglacial water pressures (Kamb, 1987). In relatively warm summers with persistent runoff (e.g. 2000), significant channelization of the basal drainage system (Fig. 2a), with a consequent fall in basal water pressures, may lead to relatively low glacier surface velocities (up to $30 \%$ greater than mean annual velocities (Fig. 3e)). In relatively cold summers with limited surface meltwater inputs (e.g. 2001), distributed drainage may persist under the lower ablation zone (Fig. 2b), allowing subglacial water pressures, and surface velocities, to remain high (up to 90\% greater than mean annual velocities (Fig. 3j)). Longitudinal stress-gradient coupling may transmit the velocity response in the lower ablation zone upstream as far as the mid-accumulation zone, where velocity variations are damped in comparison with downstream fluctuations in the lower ablation zone (Fig. 3d, e, i and j). In mid-July each year, the onset of surface runoff into moulins in the accumulation zone likely induces a late-summer period of high surface velocities downstream from the mid-accumulation zone (Fig. 3f and k). Summer surface velocities up to $10 \%$ higher than mean annual velocities in the upper accumulation zone may result from longitudinal coupling with the hydrologically forced system downstream.

These findings corroborate earlier suggestions that the flow dynamics of High Arctic glaciers are significantly influenced by supraglacial and basal hydrological conditions (Müller and Iken, 1973; Rabus and Echelmeyer, 1997; Zwally and others, 2002). They also suggest that the surface dynamics are highly sensitive to both the volume and location of supraglacial meltwater inputs to the subglacial drainage system on both intra-seasonal and intra-annual time-scales.

\section{ACKNOWLEDGEMENTS}

This research was financed by the U.K. Natural Environment Research Council ARCICE programme (grant GST/02/2202; P.W.N.) with tied studentship (GT 24/99/ARGI/16; R.G.B.); a Canadian Natural Sciences and Engineering Research Council (NSERG) operating grant; and further monies to field assistants from NSERC, the University of Alberta Canadian Circumpolar Institute, the Geological Society of America and the Northern Science Training Programme. Invaluable field support and logistics were provided by the Polar Continental Shelf Project, Natural Resources Canada (PCSP/EPCP Contribution 03202). We gratefully acknowledge S. Boon, D.
Lewis, K. Heppenstall, T. Wohlleben, J. Barker and L. Copland for field assistance, and thank the Nunavut Research Institute and communities of Grise Fiord and Resolute Bay for permission to work at John Evans Glacier. We thank D. Swift for comments on an earlier draft, P. Holmlund and C. Schneeberger for helpful reviews, and C. S. Hvidberg for editorial work on the paper.

\section{REFERENGES}

Blatter, H. 1987. On the thermal regime of an Arctic valley glacier: a study of White Glacier, Axel Heiberg Island, N.W.T., Canada. 7. Glaciol., 33(114), 200-211.

Blatter, H. and K. Hutter. 1991. Polythermal conditions in Arctic glaciers. F. Glaciol., 37(126), 261-269.

Blatter, H. and G. Kappenberger. 1988. Mass balance and thermal regime of Laika ice cap, Coburg Island, N.W.T., Canada. 7. Glaciol., 34(116), $102-110$

Copland, L. 2001. Polythermal glacier hydrology and ice flow dynamics. (Ph.D. thesis, University of Alberta.)

Copland, L. and M. Sharp. 2001. Mapping thermal and hydrological conditions beneath a polythermal glacier with radio-echo sounding. 7. Glaciol., 47(157), 232-242.

Fountain, A. G. and J. S. Walder. 1998. Water flow through temperate glaciers. Rev. Geophys., 36(3), 299-328.

Hardy, D. R. and R. S. Bradley. 1996. Climatic change in Nunavut. Geosci. Can., 23(4), 217-224.

Houghton, J.T. and 7 others, eds. 2001. The scientific basis: contribution of Working Group I to the third assessment report of the Intergovernmental Panel on Climate Change. Cambridge, etc., Cambridge University Press. Intergovernmental Panel on Climate Change.

Iken, A. 1972. Measurements of water pressure in moulins as part of a movement study of the White Glacier, Axel Heiberg Island, Northwest Territories, Canada. 7. Glaciol., 11(61), 53-58.

Kamb, B. 1987. Glacier surge mechanism based on linked cavity configuration of the basal water conduit system. F. Geophys. Res., 92(B9), 9083-9100.

Müller, F. and A. Iken. 1973. Velocity fluctuations and water regime of Arctic valley glaciers. International Association of Scientific Hydrology Publication 95 (Symposium at Cambridge 1969 - Hydrology of Glaciers ), 165-182.

Munro, D. S. 2000. Progress in glacier hydrology: a Canadian perspective. Hydrol. Processes, $14(9), 1627-1640$.

Nienow, P., M. Sharp and I. Willis. 1998. Seasonal changes in the morphology of the subglacial drainage system, Haut Glacier d'Arolla, Switzerland. Earth Surf. Processes Landforms, 23(9), 825-843.

Prowse, T. D. 1990. Northern hydrology: an overview. In Prowse, T. D. and C. S. L. Ommanney, eds. Northern Hydrology: Canadian Perspectives. Saskatoon, Sask., Environment Canada. National Hydrology Research Institute, 1-36. (NHRI Science Report 1.)

Rabus, B.T. and K. A. Echelmeyer. 1997. The flow of a polythermal glacier: McCall Glacier, Alaska, U.S.A. 7. Glaciol., 43(145), 522-536.

Scambos, T. A., C. Hulbe, M. Fahnestock and J. Bohlander. 2000. The link between climate warming and break-up of ice shelves in the Antarctic Peninsula. 7. Glaciol., 46(154), 516-530.

Skidmore, M. L. and M. J. Sharp. 1999. Drainage system behaviour of a High-Arctic polythermal glacier. Ann. Glaciol., 28, 209-215.

Wadham, J. L., R. Hodgkins, R. J. Cooper and M. Tranter. 2001. Evidence for seasonal subglacial outburst events at a polythermal glacier, Finsterwalderbreen, Svalbard. Hydrol. Processes, 15, 2259-2280.

Weertman, J. 1973. Can a water-filled crevasse reach the bottom surface of a glacier? International Association of Scientific Hydrology Publication 95 (Symposium at Cambridge 1969 - Hydrology of Glaciers), 139-145.

Willis, I. C. 1995. Intra-annual variations in glacier motion: a review. Prog. Phys. Geogr., 19(1), 61-106.

Zwally, H.J., W. Abdalati, T. Herring, K. Larson, J. Saba and K. Steffen. 2002. Surface melt-induced acceleration of Greenland ice-sheet flow. Science, 297(5579), 218-222. 